\title{
Comparison of Intrathecal Hyperbaric 0.5\% Bupivacaine and Isobaric 0.75\% Ropivacaine in Lower Limb Orthopaedic Surgeries
}

\author{
Deepak $\mathbf{R}^{1}$, Prakash Jammar ${ }^{2}$ \\ ${ }^{1}$ Assistant Professor, Department of Anaesthesia, ESIC Medical College \& PGIMSR,Chennai, India, ${ }^{2}$ Resident, Department of Critical Care, Manipal \\ Hospitals, Bangalore.
}

\section{Abstract}

Background: The study was designed to compare the efficacy of $0.75 \%$ isobaric Ropivacaine ( $3 \mathrm{ml}$ ) with $0.5 \%$ Hyperbaric Bupivacaine ( $3 \mathrm{ml}$ ) in lower limb orthopaedic surgeries. Subjects and Methods: 100 patients between 18-60 years of age, of either sex, weighing 50-90 kgs, ASA- I and ASA- II, undergoing elective lower limb orthopaedic surgeries were randomly assigned into two groups-Group B -intrathecal hyperbaric $0.5 \%$ Bupivacaine $(3 \mathrm{ml}=15 \mathrm{mg})$ and Group $\mathrm{R}$ - intrathecal isobaric $0.75 \%$ Ropivacaine $(3 \mathrm{ml}=22.5 \mathrm{mg})$. The time of onset of sensory and motor block, time of peak sensory and motor block, two segment sensory regression, motor block duration, duration of analgesia, the maximum sensory dermatomal level and side-effects were observed. Results: The time of onset of sensory and motor block was earlier in group B compared to Group $\mathrm{R}(\mathrm{p}<0.001)$. The time of peak sensory and motor block was earlier in group B compared to group $\mathrm{R}$ ( $\mathrm{p}<0.001)$. The heart rate, SBP and DBP were statistically insignificant between the two groups ( $>>0.05)$. The two dermatomal sensory regression of $B$ group was significantly prolonged compared to group $\mathrm{R}(\mathrm{p}=0.0206)$. The total duration of motor block and sensory was significantly prolonged $(\mathrm{p}<0.001)$ in group B. 30 patients $(60 \%)$ of B group and 36 patients $(72 \%)$ of R group showed a maximal sensory dermatomal level of T6. 8 patients (16\%) of group B and 10 patients (20\%) of group R showed a maximal sensory dermatomal level of T4. Five patients in group B had bradycardia $(\mathrm{p}<0.05)$. Add this new sentence in between. Seven patients in group B and one in group R had hypotension $(\mathrm{p}<0.05)$. Three patients in group B had vomiting ( $>0.05$ ). Conclusion: Ropivacaine produced satisfactory anaesthesia. Ropivacaine took a longer time to 'fix' to cause sensory and motor blockage. The lessor duration of the motor block of ropivacaine is desirable. Patient in Ropicaine group showed higher proportion of maximum level of sensory analgesia and lesser incidences of hypotension and bradycardia.

Keywords: Hyperbaric Bupivacaine, Isobaric Ropivacaine, Orthopaedic surgery.

Corresponding Author: Dr Deepak R, D26, ESIC Staff Quarters, 143 Sterling Road, Nungambakkam, Chennai 600034.

Received: May 2019

Accepted: May 2019

\section{Introduction}

Spinal anaesthesia is the most commonly used anaesthesia technique for lower limb orthopaedic surgeries. Bupivacaine is a long acting amino amide local anaesthetic and is widely used for spinal anaesthesia. Hydrophobicity appears to be a primary determinant of intrinsic anesthetic potency. ${ }^{[1]}$ Bupivacaine is a very potent local anaesthetic. ${ }^{[2]}$ However, it has cardiac and neurological side effects. ${ }^{[3]}$

Ropivacaine, a newer long-acting amide local anaesthetic, is structurally related to Bupivacaine. ${ }^{[4]}$ It is a pure $\mathrm{S}(-)$ enantiomer developed for the purpose of reducing potential toxicity and improving relative sensory and motor block profiles. ${ }^{[4]}$ It has improved safety profile because of its lesser cardiac toxicity and lesser CNS side effects. ${ }^{[4]}$

Ropivacaine have a CNS-to-cardiovascular toxicity ratio intermediate between that of lidocaine and bupivacaine. ${ }^{[5,6]}$ Ropivacaine has less impact on cardiac conduction and the frequency of arrhythmias than local anesthetics do at blood levels producing systemic toxicity. ${ }^{[5]}$

Although ropivacaine appears to produce less motor block and slightly shorter duration of action as compared to bupivacaine, the clinical effect of Ropivacaine is difficult to separate in an individual patient. ${ }^{[7]}$ Ropivacaine has intrinsic vasoconstrictive property.

At low concentrations, ropivacaine has differential blocking effect on nerve fibres. A good differentiation between sensory and motor block can be elicited with ropivacaine. Ropivacaine blocks fibres responsible for transmission of pain (A delta and $\mathrm{C}$ fibres) more completely than those that control motor function (A beta fibres). ${ }^{[8]}$

Its intrathecal doses used in clinical studies have ranged from 8 to $22.5 \mathrm{mg}$. However, ropivacaine is less potent than bupivacaine. ${ }^{[8-10]}$ Ropivacaine was found to be $60 \%$ as potent as bupivacaine. ${ }^{[11]}$ The dose-ratio ropivacaine:bupivacaine showing similar profiles of effects was 3:2, and, at equal doses, anesthesia was less intense using ropivacaine. ${ }^{[12]}$

In our study we compared the effects and side effects of intrathecal hyperbaric $0.5 \%$ bupivacaine with intrathecal $0.75 \%$ isobaric ropivacaine.

\section{$\underline{\text { Aim of the study }}$}

The aim of our study was to compare the effects and side effects of $0.5 \%$ hyperbaric bupivacaine with $0.75 \%$ isobaric 
ropivacaine in elective lower limb surgeries. Our primary objective was to observe and compare the sensory and motor block characteristics of the two drugs by observing the time of onset, time of maximum block, time for two segment regression, total duration of each block and the maximal level of the sensory block. Our secondary objective was to compare the side effects of the two drugs.

\section{Subjects and Methods}

After obtaining approval from the ethical committee and informed written consent, we recruited 100 patients of ASA 1 and 2 posted for elective lower limb orthopedic surgeries. The sample size was calculated to be 40 in each group. We however took 50 patients in each groups to compensate for any drop outs during the study.

\section{The inclusion criteria of the study were:}

Age $18-60$ years

Both gender

Lower limb orthopaedic surgery

ASA physical status i and II

\section{The exclusion criteria were}

Patient unwilling

Any bleeding disorder or patient on anticoagulants

Neurological and musculoskeletal disease

Local infection at the injection site

History of allergy to local anaesthetic and signs of allergy to lignocaine test dose

Significant history of drug/alcohol abuse

Patients with Cardiac arrhythmias

Patients with any other contraindication for regional anaesthesia

Patients were randomly divided into two groups based on slips in the box technique. Group B received $3 \mathrm{ml} 0.5 \%$ hyperbaric bupivacaine and Group $\mathrm{R}$ received $3 \mathrm{ml} 0.75 \%$ isobaric ropivacaine for spinal anaesthesia. The anaesthesiologist who did the randomization and prepared the study drugs with coded labels did not participate in the observation of the study parameters.

Preoperative assessment was done in our PAC clinic. After detailed history and physical examination, these investigations- hematocrit; RFT, CBC, blood grouping, platelet count, chest radiography and ECG was done. A day prior to surgery, patients were re-examined. The patients were kept nil per orally 10 hours prior to surgery. All patients were given tablet alprazolam $0.5 \mathrm{mg}$ night before surgery. Informed written consent was taken from all patents. On the day of surgery, intravenous cannulation of all patients was done with 18 gauge cannula and ringer lactate $500 \mathrm{ml}$ was given in the pre-operative room. On taking the patients to the operation theatre, multipara monitors were connectedECG, SpO2, BP, heart rate.

After putting the patient in sitting position, under all aseptic precautions lumbar puncture was done at L3 L4 interspace with 25 gauge quinke spinal needle. Patient was immediately placed in supine position. The time of spinal anaesthesia was taken as time zero.
Sensory blockade was assessed by alcohol swab method in the mid-axillary line bilaterally. The motor block was assessed by modified Bromage scale.

\begin{tabular}{l}
\hline Scale 1: Modified Bromage Scale \\
\begin{tabular}{|l|l|}
\hline Score & Criteria \\
\hline 0 & No motor block \\
\hline 1 & $\begin{array}{l}\text { Inability to raise extended leg; able to move knees and } \\
\text { feet }\end{array}$ \\
\hline 2 & $\begin{array}{l}\text { Inability to raise extended leg and move knee; able to } \\
\text { move feet }\end{array}$ \\
\hline 3 & Complete block of motor limb \\
\hline
\end{tabular}
\end{tabular}

The onset of sensory and motor block, the time for maximum sensory and motor block, two segment sensory regression, motor and sensory duration was noted in minutes. The patient was asked at the interval of every 15 seconds to assess sensory or motor block onset.

The following readings were noted for assessment of onset of blockade:

T0 - Time of Spinal anesthesia

Time 1 (TSO) - Onset of sensory blockade is defined as the time taken from the time of spinal anaesthesia till the patient did not feel the cold sensation at T12 level

Time 2 (TMO) - Onset of motor block is defined as the time from spinal injection until Bromage 1 score is obtained.

Time 3 (TSP) - Time taken for peak/maximum sensory blockade is defined as the time of spinal anaesthesia to the maximum sensory blockade attained.

Time 4 (TMP) - Time taken for peak/maximum motor block is defined as the time of spinal anaesthesia until Bromage 3 score is obtained.

The vital parameters were continuously observed throughout the surgery, recovery room and post operative ward.

Hypotension was defined as SBP of less than $20 \%$ of the baseline or SBP less than $90 \mathrm{mmHg}$. Bradycardia was defined as heart rate of less than 55 per minute. Hypotension was treated with incremental doses of mephentermine $6 \mathrm{mg}$ and bradycardia with it atropine $0.6 \mathrm{mg}$. Shivering was treated with warm iv fluids and tramadol 50 iv or intravenously slowly. Any other side effects were noted and treated with appropriate drugs.

The following parameters were noted in the post-operative period:-

Time 5 (TSR)- Two segment sensory regression time is the time taken for the sensory block to regress by two segments from the maximum level of sensory blockade.

Time 6 (TMD)- Duration of motor blockade is duration from the time of spinal anaesthesia to motor recovery (to Bromage 0).

Time 7 (TSD)- Duration of analgesia is taken as the time of spinal anaesthesia to the time the patients were asked to report early for any pain. (pain is asked to report early for any pain so that a good estimate of time is made).

VAS (Visual Analogue Scale) was used to assess pain postoperatively. When the VAS score was 5 or more, the patient was given rescue post-operative analgesia with injection paracetamol $1 \mathrm{~g}$ iv, followed by iv tramadol $50 \mathrm{mg}$ if required.

\section{Statistical analysis}


The observed time parameters in each of the two groups were analysed by statistical measurements -means and standard deviation. The quantitative data between the two groups was compared by independent $t$ test.

\section{Results}

On comparing the demographic data, height and weight both the groups were found to be comparable ( $p$ value $>0.05$ ) [Table 1]

Table 1: Age, weight and height parameters between the groups.

\begin{tabular}{|l|l|l|l|}
\hline $\begin{array}{l}\text { Demographic } \\
\text { Parameters }\end{array}$ & $\begin{array}{l}\text { Group B }(\mathbf{n}=50) \\
\text { mean } \pm \text { SD }\end{array}$ & $\begin{array}{l}\text { Group R }(\mathbf{n}=50) \\
\text { mean } \pm \text { SD }\end{array}$ & p value \\
\hline age $($ years $)$ & $41.26 \pm 8.03$ & $43.92 \pm 8.97$ & 0.125 \\
\hline height $(\mathrm{cm})$ & $161.08 \pm 6.95$ & $163.62 \pm 7.86$ & 0.0937 \\
\hline weight $(\mathrm{kg})$ & $61.24 \pm 10.14$ & $59.64 \pm 7.42$ & 0.374 \\
\hline
\end{tabular}

The senory onset time of the bupivacaine group was $3.79+/-$ $0.99 \mathrm{~min}$ and that of the ropivacaine group was $5.160+/-$ $0.97 \mathrm{~min}$. The difference was statistically very significant $(\mathrm{p}<0.0001)$.

\begin{tabular}{|l|l|l|}
\hline Table 2: Time of onset of sensory block (in minutes) \\
\hline $\mathbf{n = 5 0}$ & Group B & Group R \\
\hline Mean & 3.79 & 5.16 \\
\hline Standard Deviation & 0.99 & 0.97 \\
\hline p value & & $<0.0001$ \\
\hline
\end{tabular}

The motor onset time of the bupivacaine group was $4.92 \pm$ 0.66 as compared to that of the ropivacaine group of $8.61 \pm$ 1.74. The difference was statistically very significant $(\mathrm{p}<0.0001)$.

\begin{tabular}{|l|l|l|}
\hline Table 3: Time of onset of motor block (in minutes) \\
\hline $\mathbf{n = 5 0}$ & Group B & Group R \\
\hline Mean & 4.92 & 8.61 \\
\hline Standard Deviation & 0.66 & 1.73 \\
\hline p value & & $<0.0001$ \\
\hline
\end{tabular}

The time for maximum sensory block in the bupivacaine group was $8.02 \pm 1.22$ as compared to that in the ropivacaine group $13.96 \pm 1.94$. The difference was statistically very significant $(\mathrm{p}<0.0001)$.

Table 4: Time of Maximum sensory block (in minutes)
\begin{tabular}{|l|l|l|}
\hline $\mathbf{n = 5 0}$ & Group B & Group R \\
\hline Mean & 8.02 & 13.96 \\
\hline Standard Deviation & 1.22 & 1.94 \\
\hline p value & & $<0.0001$ \\
\hline
\end{tabular}

The time for the maximum motor block in the bupivacaine group was $8.52 \pm 1.28$ and that in the ropivacaine group was $16.32 \pm 2.27$. The difference was statistically very significant. $(\mathrm{p}<0.0001)$. [Table 2]

Table 5: Time of maximum motor block (in minutes)

\begin{tabular}{|l|l|l|}
\hline $\mathbf{n = 5 0}$ & Group B & Group R \\
\hline Mean & 8.52 & 16.32 \\
\hline Standard Deviation & 1.28 & 2.27 \\
\hline p value & & $<0.0001$ \\
\hline
\end{tabular}

The time for two segment sensory regression in the bupivacaine group was $110.52+/-15.38$ min where as it was $102+/-19.09$. The difference was satistically significant $(p=0.0206)$. The total duration of the motor block in the bupivacaine group was $182.68+/-20.11 \mathrm{~min}$ as compared to that in the ropivacaine group which was $139.76+/-11.39$ min. The difference was statistically very significant $(p<0.0001)$. The total duration of the sensory block/analgesia (and the time for first pain relief medication) was $216.78+/-$ $26.37 \mathrm{~min}$ for bupivacaine whereas that in the ropivacaine group was $186.34+/-25.53 \mathrm{~min}$. The difference was statistically very significant $(\mathrm{p}<0.0001)$. [Table 3]

Table 6: Time of two segment sensory regression, motor and sensory duration ( in minutes).

\begin{tabular}{|l|l|l|l|}
\hline $\begin{array}{l}\text { Time } \\
\text { Parameters }\end{array}$ & $\begin{array}{l}\text { Group } \\
(\mathbf{n = 5 0}) \\
\text { mean } \pm \text { SD }\end{array}$ & $\begin{array}{l}\text { Group } \\
(\mathbf{n = 5 0}) \\
\text { mean } \pm \text { SD }\end{array}$ & R value \\
\hline TSR $(\min )$ & $110.52 \pm$ & $102.36 \pm$ & 0.0206 \\
& 15.38 & 19.09 & \\
\hline TMD $(\min )$ & $182.68 \pm$ & $139.76 \pm$ & $<0.0001$ \\
& 20.11 & 11.39 & \\
\hline $\begin{array}{l}\text { TSD }(\min ) \\
\begin{array}{l}\text { Duration } \\
\text { Analgesia }\end{array}\end{array}$ & $216.78 \pm$ & $186.34 \pm$ & $<0.0001$ \\
\hline
\end{tabular}

In the bupivacaine group seven patients had hypotension, five patients had bradycardia and three patients had nausea/vomiting $(p<0.05)$. Only one patient in the ropivacaine group had hypotension $(\mathrm{p}>0.05)$.

\begin{tabular}{|c|c|c|c|c|c|}
\hline Side effects & $\begin{array}{l}\text { Group } \\
(\mathbf{n}=\mathbf{5 0})\end{array}$ & B & $\begin{array}{l}\text { Group } \\
(\mathrm{n}=\mathbf{5 0})\end{array}$ & $\mathbf{R}$ & p value \\
\hline hypotension & 7 & & 1 & & 0.0291 \\
\hline bradycardia & 5 & & 0 & & 0.0230 \\
\hline nausea vomiting & 3 & & 0 & & 0.0832 \\
\hline
\end{tabular}

Maximum level of sensory block attained in each group In the Bupivacaine group, 30 patients (out of 50) had the maximum sensory block level T6, 8 patients had maximum block level at T4, 7 patients at T8 level, 3 patients at T10 level and 2 patients at T12 level. In the Ropivacaine group, 36 patients had a maximum block level at T6, 10 patients at T4 level and 4 patients at T8 level.

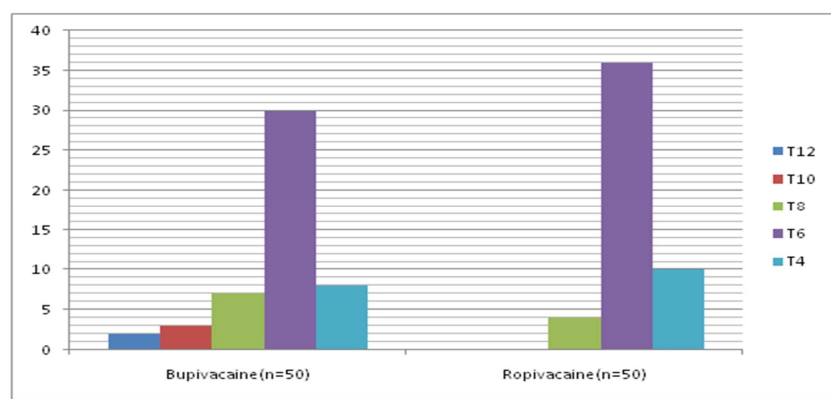

Figure 1: Maximum level of sensory block attained in each group

The changes in the heart rate, systolic blood pressure, diastolic blood pressure and the mean blood pressure were statistically insignificant between the two groups ( $p>0.05)$. 


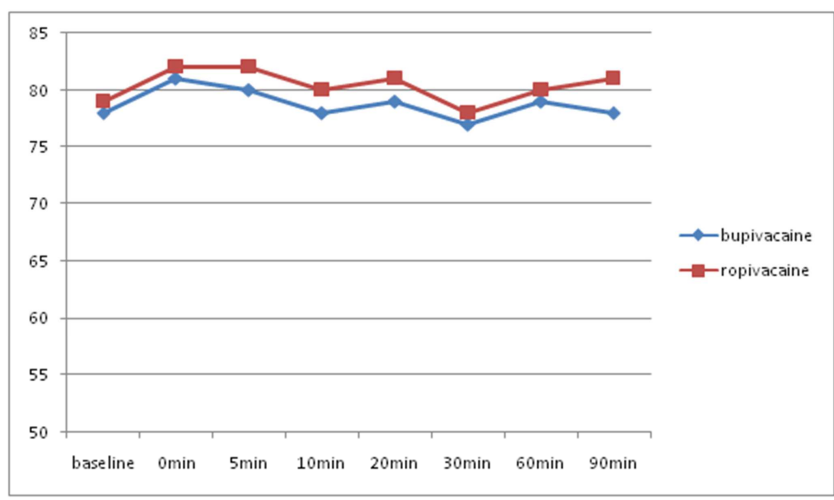

Graph 1: Changes in the Heart Rate

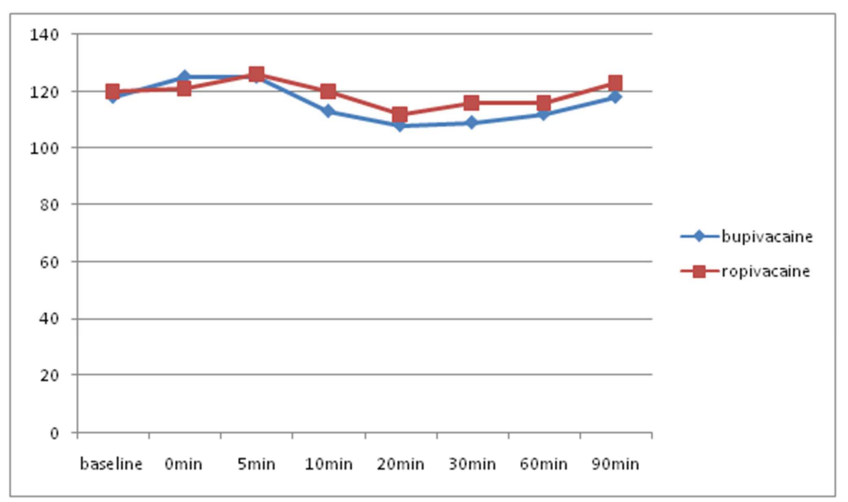

Graph 2: Changes in the systolic blood pressure

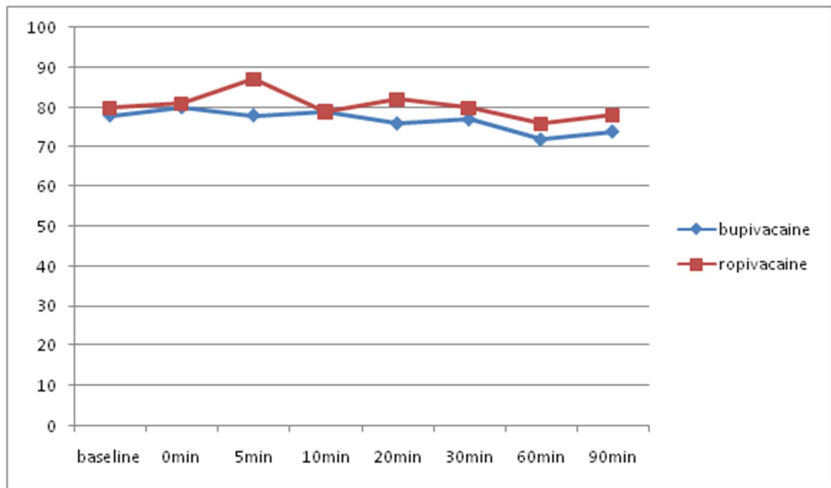

Graph 3: Changes in the diastolic blood pressure

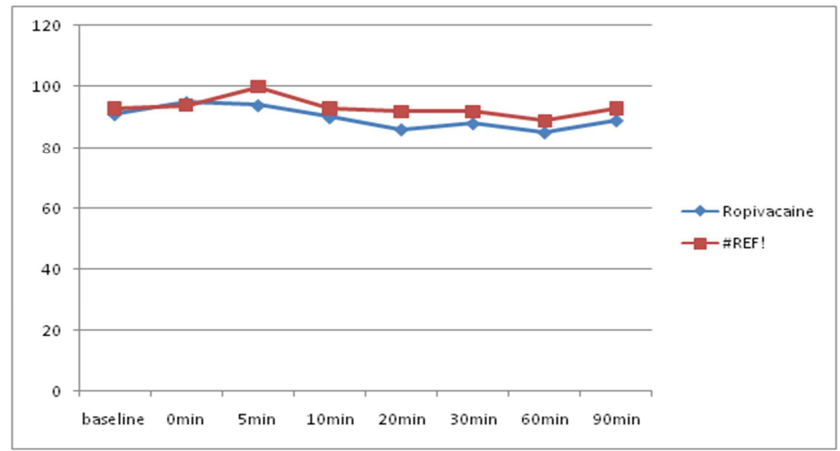

Graph 4: Changes in the mean arterial pressure

\section{Discussion}

Bupivacaine is the most commonly used drug for spinal anaesthesia. ${ }^{[32]}$ Ropivacaine is known to have a better safety profile compared to bupivacaine as it is less lipophilic and has less cardiac toxicity. Ropivacaine acts on A delta and $\mathrm{C}$ fibers (sensory) preferentially to A beta fibers ( motor) which is desirable in day care surgeries under spinal anaesthesia. We compared equivalent doses of hyperbaric bupivacaine with isobaric ropivacaine in lower limb orthopaedic surgeries by observing its block characteristics to study its efficacy and by observing its side effects. There were no drop outs in our study. Both the study groups were comparable in the demographic characteristics. ( $p>0.05$ ).

In our study we noted a statistically significant faster onset of sensory and motor block with bupivacaine in comparison to ropivacaine. Bupivacaine 'fixed' early to attain the statistically significant peak sensory and motor block. The two segment sensory recession of bupivacaine was longer for bupivacaine as compared to ropivacaine and statistically significant. The duration of motor and sensory block was longer for bupivacaine which was statistically significant. However, the incidences of hypotension and bradycardia was higher in bupivacaine on comparison with ropivacaine. In Bupivacaine $60 \%$ patients (30 patients) attained a maximum level of T6 and 16\% (8 patients) attained level of T4. In the Ropivacaine group, $72 \%$ patients (36 patients) attained a maximum sensory level of T6 and 20\% (10 patients) attained maximum level of $\mathrm{T} 4$.

In our study we noted a favourable spinal anaesthesia block characterstics of both bupivacaine and ropivacaine. Although ropivacaine was slower in onset and to attain peak sensory and motor block, it provided satisfactory anaesthesia in terms of sensory and motor duration for an orthopaedic surgery. The shorter duration of motor block of ropivacaine is desirable in a surgery done on a day care setting. Although ropivacaine had a statistically significant shorter duration of sensory block, as compared to bupivacaine, the analgesia or the sensory duration can be extended by adding adjuvants. The decreased duration of motor block of ropivacaine is favourable as the patient feels comfortable postoperatively. The likely post-operative anxiety due to the dense motor block due to bupivacaine could be prevented by using alternatives like ropivacaine. Also ropivacaine has lesser side effects which gives it an upper hand to use as an alternative for bupivacaine for surgeries below umbilicus of intermediate duration.

Gaurav Kuthiala et al, ${ }^{[13]}$ in his review article reported that ropivacaine being less lipid soluble is less likely to penetrate large myelinated motor nerve fibres and lesser motor blockade. Lesser lipophilicity implies lesser cardiac and nervous system toxicity. Ropivacaine also shows higher degree of sensory and motor differentiation. Ropivacaine is desirable when lesser degree and duration of motor block is needed. In our study, Ropivacaine group showed higher maximum sensory block compared to bupivacaine group, whereas the motor block duration of ropivacaine was lesser with bupivacine. ${ }^{[13]}$

Kallio et al, ${ }^{[14]}$ compared intrathecal ropivacaine $(15 \mathrm{mg}$, $20 \mathrm{mg}$ ) with bupivacaine $(10 \mathrm{mg}$ ) in 90 patients in three groups. The authors observed that Ropivacaine $15 \mathrm{mg}$ provided faster recovery of motor block $(150 \mathrm{~min})$ than bupivacaine $10 \mathrm{mg}(210 \mathrm{~min} ; \mathrm{P}=0.005)$. The authors concluded that the duration of sensory block of ropivacaine was two thirds and the duration of motor block was half 
when compared with bupivacaine. ${ }^{[14]}$

Boztuğ N1 et al. ${ }^{[15]}$ compared isobaric ropivacaine(15mg) with bupivacaine $(7.5 \mathrm{mg})$ for outpatient arthroscopic knee surgery in 90 patients posted for arthroscopic knee surgery. The authors observed the haemodynamic parameters, first ambulation and first urination were similar in the two groups. Isobaric ropivacaine $15 \mathrm{mg}$ provided a higher sensory block level and shorter sensory onset and onset times as compared to $7.5 \mathrm{mg}$ bupivacaine. The findings of this study coorelates with our study. ${ }^{[15]}$

Amitava Layek et al, ${ }^{[16]}$ compared intrathecal isobaric $0.5 \%$ $3 \mathrm{ml}$ ropivacaine + fentanyl $(\mathrm{RF})$ and $0.5 \% 3 \mathrm{ml}$ bupivacaine + fentanyl (BF)in adult patients undergoing lower limb orthopedic surgery in 74, ASA 1 and 2 patients. Haemodynamic parameters were comparable in both groups. The authors concluded that bupivacaine fentanyl group showed significantly longer duration of sensory and motor block as compared to ropivacaine-fentanyl. As ropivacaine gives a shorter sensory and motor block it may be preferred in day care surgery. The findings of our study, coorelates with this study.

Suresh Kumar et al, ${ }^{[17]}$ compared intrathecal isobaric ropivacaine with bupivacaine to assess the postoperative recovery profile in patients posted for arthoscopic knee surgery in 90 ASA 1 and patients. The authors concluded that isobaric ropivacaine was associated with longer onset and shorter duration of sensory and motor block, increased postoperative analgesic reqirement and similar discharge times as compared to bupivacaine. The sensory and motor block characteristics of our study coorelates with this study.

Sonal Bhat et $\mathrm{al}^{[18]}$ compared intrathecal isobaric bupivacaine $(0.5 \%, 3 \mathrm{ml})$ versus isobaric ropivacaine $(0.75 \%$, $3 \mathrm{ml}$ ) in lower abdominal surgeries in 70 ASA 1 and 2 patients. The regression of sensory blockade in ropivacaine group was faster $(\mathrm{P}<0.001)$. The duration of motor blockade was shorter in ropivacaine group. $(p<0.05)$. Excellent analgesia,stable haemodynamics and no side effects were seen in ropivacaine group. The authors concluded that ropivacaine was safe and effective for early motor recovery and ambulation. ${ }^{[18]}$

The studies done by Erturk et al ${ }^{[19]}$ Luck et al, ${ }^{[21]} \mathrm{O} \mathrm{Al}-$

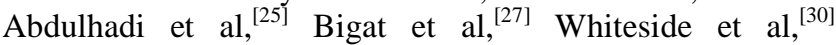
suggests that bupivacaine showed earlier onset of sensory and motor block and longer duration of sensory and motor block compared to ropivacaine. Additionally studies done by Ying.Y.Lee et al, ${ }^{[20]}$ Stafania Leone et al, ${ }^{[2]}$ Marc Van De Velde et al, ${ }^{[23]}$ Camorcia et al, ${ }^{[2]}$ Malinovsky et al, ${ }^{[31]}$ suggested that Bupivacaine was more potent than ropivacaine. Copperjans et al, ${ }^{[26]}$ concluded that Ropivacaine required $50 \%$ higher dose as compared to racemic bupivacine.

Whiteside et al, ${ }^{[30]}$ showed ropivacaine to have a favourable recovery profile as compared to bupivacaie in day care surgeries. Patients in Ropivacaine group in the study done by O Al-Abdulhadi et al, ${ }^{[25]}$ showed higher satisfacation levels in spinal anaestheseia as compared to that in Bupivacaine. Anaesthesia was percieved to be effective in $97 \%$ of patients given bupivacaine, and $87 \%$ with Ropivacaine in the study done by Gautier $\mathrm{P}$ et al. ${ }^{[29]}$ Casati et al, ${ }^{[28]}$ concluded that ropivacaine and levobupivacaine were acceptable alternatives for bupivacaine in ingunial hernia repair surgeries under spinal anaesthesia.

\section{Conclusion}

Ropivacaine produced satisfacory anaesthesia for lower limb orthopaedic surgeries. The lesser duration of the motor block of ropivacaine is desirable in orthopaedic surgeries of short and intermediate duration. Although ropivacaine showed shorter duration of sensory block compared to bupivacaine, the duration of the sensory block can be enhanced by adding intrathecal adjuvants. This will benefit patients posted for day care surgeries.

Ropivacaine took a longer time to 'fix' to cause sensory and motor blockage.

Ropivacaine showed higher proportion of maximum level of sensory analgesia and showed lesser incidences of hypotension and bradycardia.

The lesser duration of motor block, the higher level of maximum sensory block and lesser side effects make ropivacaine a safe alternative for intrathecal administraion in lower limb surgeries.

\section{Acknowledgements}

I acknowledge my institute for providing me the resources required for the study.

\section{References}

1. Courtney K, Strichartz G: Structural elements which determine local anesthetic activity. In: Schwartz GR, ed. Handbook of Experimental Pharmacology: Local Anesthetics, Berlin: Springer-Verlag; 1987:5389.

2. Strichartz GR, Sanchez V, Arthur GR, et al: Fundamental properties of local anesthetics. II. Measured octanol : buffer partition coefficients and pKa values of clinically used drugs. Anesth Analg 71:158-170, 1990.

3. Rosen MA, Thigpen JW, Shnider SM, et al: Bupivacaine induced cardiotoxicity in hypoxic and acidotic sheep. Anesth Analg 1985; 64:1089-1096.

4. Hansen TG. Ropivacaine: A pharmacological review. Expert Rev Neurother 2004:4:781-91.

5. Moller R, Covino BG: Cardiac electrophysiologic properties of bupivacaine and lidocaine compared with those of Ropivacainee, a new amide local anesthetic. Anesthesiology 1990; 72:322.

6. Kopacz DJ, Allen HW: Accidental intravenous levobupivacaine. Anesth Analg 1999; 89:1027.]

7. McClure JH: Ropivacaine. Br J Anaesth 1996; 76:300

8. Kuthiala G, Chaudhary G. Ropivacaine: A review of its pharmacology and clinical use. Indian J Anaesth2011; 55:104 10.

9. KashimotoS Kume $\mathrm{M}$ and Kumazawa. Functional and metabolic effects of bupivacaine and lignocaine in the rat heart-lung preparation. Br J Anaesth 1990;65(4):521-526.

10. Graf BM, Abraham I, Eberbach N, Kunst G, Stowe DF, MartinE. Differences in cardiotoxicity of bupivacaine and ropivacaine are the result of physicochemical and stereoselective properties. Anesthesiology 2002; 96:1427 34.

11. Capogna G1, Celleno D, Fusco P, Lyons G, Columb M. Relative potencies of bupivacaine and ropivacaine for analgesia in labour. $\mathrm{Br} \mathrm{J}$ Anaesth. 1999 Mar;82(3):371-3.

12. Malinovsky JM, Charles F, Kick O, Lepage JY, MalingeCozian A, et al. Intrathecal anesthesia: Ropivacaine versus bupivacaine. AnesthAnalg 2000; 91:1457 60

13. Gaurav Kuthiala and Geeta Chaudhary1. Ropivacaine: A review of its pharmacology and clinical use. Indian J Anaesth. 2011 Mar-Apr; 55(2): 104-110. doi: 10.4103/0019-5049.79875]

14. Kallio H1, Snäll EV, Kero MP, Rosenberg PH. A comparison of intrathecal plain solutions containing ropivacaine 20 or $15 \mathrm{mg}$ versus bupivacaine $10 \mathrm{mg}$. Anesth Analg. 2004 Sep;99(3):713-7 
15. Boztuğ N1, Bigat Z, Karsli B, Saykal N, Ertok E. Comparison of ropivacaine and bupivacaine for intrathecal anesthesia during outpatient arthroscopic surgery. J Clin Anesth. 2006 Nov;18(7):521-5.

16. Amitava Layek, Souvik Maitra, Nitish K Gozi, Sulagna Bhattacharjee, Sugata Pal, Suvadeep Sen, and Avijit Hazra. Comparison between intrathecal isobaric ropivacaine-fentanyl and bupivacaine-fentanyl in elective infraumbilical orthopedic surgery: A randomized controlled study. J Anaesthesiol Clin Pharmacol. 2015 Oct-Dec; 31(4): 542-546. doi: $10.4103 / 0970-9185.169086$

17. Kumar S Suresh, Talwar Vandana, Gupta Poonam, Gogia Anoop Raj. Comparison of the efficacy of intrathecal isobaric ropivacaine and bupivacaine in day care knee arthroscopy: A randomized controlled trial. Anesth Essays Res. 2018 Sep-Dec; 12(4): 859-86.

18. Sonal N. Bhat, Himaldev, and Madhusudan Upadya. Comparison of efficacy and safety of ropivacaine with bupivacaine for intrathecal anesthesia for lower abdominal and lower limb surgeries. Anesth Essays Res. 2013 Sep-Dec; 7(3): 381-385. doi: 10.4103/02591162.123252

19. Erturk E, Tutuncu C, Eroglu A, Gokben M. Clinical comparison of 12 $\mathrm{mg}$ ropivacaine and $8 \mathrm{mg}$ bupivacaine, both with 20 microg fentanyl, in spinal anaesthesia for major orthopaedic surgery in geriatric patients. Med PrincPract. 2010;19:142-7.

20. Lee YY, Kee WDN, Fong SY, Liu JT, Gin T. The median effective dose of bupivacaine, levobupivacaine, and ropivacaine after intrathecal injection in lower limb surgery. AnesthAnalg. 2009;109(4):13311334.

21. Luck JF, Fettes PD, Wildsmith JA. Spinal anaesthesia for elective surgery: A comparison of hyperbaric solutions of racemic bupivacaine, levobupivacaine, and ropivacaine. Br JAnaesth 2008; 101:705 10.

22. Leone S, Di Cianni S, Casati A, Fanelli G. Pharmacology, toxicology, and clinical use of new long acting local anesthetics, ropivacaine and levobupivacaine. Acta Biomed. 2008;79(2):92- 105.

23. Marc Van de Velde;Rebekka Dreelinck;Jasperina Dubois;Ariane Kumar;Jan Deprest;Liesbeth Lewi;Eugene Vandermeersch;Determination of the Full Dose-Response Relation of Intrathecal Bupivacaine, Levobupivacaine, and Ropivacaine, Combined with Sufentanil, for Labor Analgesia. Anesthesiology. 106(1):149-156, JAN 2007
24. Camorcia M, Capogna G, Berritta C, Columb MO. The relative potencies for motor block after intrathecal ropivacaine, levobupivacaine, and bupivacaine. AnesthAnalg. 2007;104(4):904907.

25. Al-Abdulhadi O, Biehl D, Ong B, Boker A. Hyperbaric spinal for elective Cesarean section - Ropivacaine vs bupivacaine. Middle East J Anaesthesiol. 2007; 19:385-96.

26. Coppejans HC, Vercauteren MP. Low-dose combined spinal- epidural anesthesia for cesarean delivery: a comparison of three plain local anesthetics. Acta Ana Esthesiologica Belg. 2006;57(1):39

27. Bigat Z, Boztug N, Karsli B, Cete N, Ertok E. Comparison of hyperbaric ropivacaine and hyperbaric bupivacaine in unilateral spinal anaesthesia. Clin Drug Investig. 2006;26:35-41.

28. Casati A, Moizo E, Marchetti C, Vinciguerra F. A prospective,randomized, double-blind comparison of unilateral spinal anesthesia with hyperbaric bupivacaine, ropivacaine, or levobupivacaine for inguinal herniorrhaphy. AnesthAnalg. 2004;99(5):1387-1392.

29. Gautier P, De Kock M, Huberty L, Demir T, Izydorczic M, Vanderick B. Comparison of the effects of intrathecal ropivacaine, levobupivacaine, and bupivacaine for Caesarean section. Br J Anaesth. 2003;91(5):684-689.

30. Whiteside JB, Burke D, Wildsmith JAW. Comparison of ropivacaine $0.5 \%$ (in glucose $5 \%$ ) with bupivacaine $0.5 \%$ (in glucose $8 \%$ ) for spinal anaesthesia for elective surgery. Br J Anaesth. 2003;90(3):304-308.

31. Malinovsky JM, Charles F, Kick O, Lepage JY, MalingeCozian A, et al. Intrathecal anesthesia: Ropivacaine versus bupivacaine. AnesthAnalg 2000; 91:1457 60

32. Vishal Uppal1, Harsha Shanthanna2, Christopher Prabhakar3, Dolores $\mathrm{M}$ McKeen1. Intrathecal hyperbaric versus isobaric bupivacaine for adult non-caesarean-section surgery: systematic review protocol. https://bmjopen.bmj.com/content/6/5/e010885

33. Karin P.W. Schoenmakers, Maaike G.E. Fenten, Jan Willem Louwerens, Gert Jan Scheffer and Rudolf Stienstra. The effects of adding epinephrine to ropivacaine for popliteal nerve block on the duration of postoperative analgesia: a randomized controlled trial. BMC Anesthesiology201515:100

Copyright: () the author(s), publisher. Academia Anesthesiologica International is an Official Publication of "Society for Health Care \& Research Development". It is an open-access article distributed under the terms of the Creative Commons Attribution Non-Commercial License, which permits unrestricted non-commercial use, distribution, and reproduction in any medium, provided the original work is properly cited.

How to cite this article: Deepak R, Jammar P. Comparison of Intrathecal Hyperbaric 0.5\% Bupivacaine and Isobaric 0.75\% Ropivacaine in Lower Limb Orthopaedic Surgeries. Acad. Anesthesiol. Int. 2019;4(1):115-120.

DOI: dx.doi.org/10.21276/aan.2019.4.1.27

Source of Support: Nil, Conflict of Interest: None declared. 